\title{
Contraceptive prevalence in Dembia District, northwest Ethiopia
}

\author{
Yigzaw Kebede
}

\begin{abstract}
Background: Inadequate family planning services exist in Ethiopia, where total fertility and population growth rates are markedly high.

Objective: This study is aimed at assessing family planning coverage and the main factors that are associated with the usage of contraceptives among women in the 15-49 years age group.

Methods: A cross sectional community based study was conducted in April 2004 in Dembia District, northwest Ethiopia. Using the multistage sampling technique, a total of 1340 women in one urban and three rural kebeles were selected for the study. A questionnaire interview was also used for data collection.

Result: It was found that $392(71.3 \%)$ respondents from the urban kebele and $354(44.8 \%)$ in the rural kebeles of the district had information about family planning. Three hundred and nine women $(23.1 \%)$ had ever used modern family planning methods. The current CPR in the district was found to be $12.3 \%(22.5 \%$ in the urban kebele and $5.2 \%$ in the rural kebeles) and most women (64.2\%) used injectable contraceptives. A total of 144 (46.6\%) women who had ever used contraceptives have discontinued taking contraceptives. Of those women who had never used contraceptives, 728 $(70.5 \%)$ said they did not want to take contraceptives in the future. Residence, distance from health institutions, age of the women, education of the woman and the husband, as well as occupation, and religion were found to be significantly associated with the usage of contraceptives.

Conclusion: CPR is low in the district, especially in rural areas. Strategies like out reach programs and the training of Community based reproductive health agents (CBRHAs) needs to be considered to increase the coverage of family planning services in the area. [Ethiop.J.Health Dev. 2006;20(1):32-38]
\end{abstract}

\section{Introduction}

In 2004 the world's population was estimated to be around 6.4 billion, of which Africa constitutes $13.84 \%$ $(885,000,000)$. The population of Ethiopia is about 72.4 million $(8.2 \%$ of the African population). The total global fertility is 2.8 but Ethiopia has a total fertility rate of 5.9. Similarly the percentage of married women (1549 years old) who are using modern contraceptives in the world is $53 \%$ and the percentage for Ethiopia is $6(1,2)$. The global population growth rate is $1.3 \%$ but Ethiopia has a growth rate of $2.7 \%$ (3). This shows that the population growth rate in Ethiopia is high. The maternal mortality is also high in Ethiopia (871 per 100,000 live births) (4). Family planning is considered as one of the strategies for reducing the population growth rate, as well as maternal mortality and child mortality rates (5-8).

The national family planning coverage of Ethiopia in 1992, 1993, 1994, and 1995 (E.C) was 13.34\%, 18.7\%, $17.23 \%$, and $21.46 \%$, respectively. In the same years, the coverage for Amhara Region was $16.8 \%, 21.4 \%$, $19.44 \%, 22.16 \%$, respectively $(3,9,10,11)$. A survey done in 1994 revealed the current prevalence rate of family planning to be $8.6 \%$ (26.5\% urban \& $2 \%$ rural) in North Gondar Zone (12). In 1999 the contraceptive prevalence rate in Gondar town \& the surrounding peasant associations was found to be $35.5 \%$ \& $11 \%$, respectively. In this study injectable contraceptives were found to be the widely used methods of contraception (13). A similar survey done in 1996 in Dabat District,
North Gondar Zone, revealed that $4.6 \%$ of the women who had committed sexual intercourse had used contraceptives. The current contraceptive prevalence rate was $2.4 \%$ for the whole district. While the CPR in Dabat, the main town of the district was $12.5 \%$ and the coverage in the rural areas was $0.91 \%$. In this same survey, the desire by families for more children $(68.1 \%)$, the lack of knowledge about contraceptives (10.7\%), the lack of access to contraceptives (4.2\%), and fear of side effects $(4.2 \%)$ were reported as prominent reasons for not using contraceptives. Of those people who have ever used contraceptives, $79.4 \%$ have used pills, followed by injectables $(22.8 \%)(14)$. In a study conducted around Jimma town, a current CPR of $7.0 \%$ among married women was reported, of which $65.0 \%$ had used the pills (15). In 1995 about $42 \%$ of the married women in Addis Ababa were found to use contraceptives (16). Studies in different parts of Ethiopia showed very high rates of unmet need for contraceptives-as high as $49 \%$ in Addis Ababa $(17,18)$. In developing countries in general, it is known that more than one woman in every five wants to avoid pregnancy but is not using contraceptives (19). In Ethiopia, the deployment of CBD agents among communities showed an increase in CPR(20). In general, CPR is increasing in urban settings $(16,19,21)$. In several studies factors like age, educational status, the number of living children, religion, occupational status, and area of residence were found to be associated with the usage of family planning methods $(12-16,21)$.

Department of Community Health, Faculty of Medicine and Health Sciences, University of Gondar, P.O.Box 196, Gondar, Ethiopia 
This study is justified since no recent family planning survey has been conducted in Dembia district and other similar areas in North Gondar Administrative Zone. The study is expected to help health managers and reproductive health service providers in this and other similar areas to determine where they stand in terms of family planning coverage. The main objective of this survey was to assess the family planning coverage in the district and the main factors that are associated with the usage of contraceptives among women of reproductive age (15-49 years).

\section{Methods}

A cross sectional, community based study was conducted in April 2004 in Dembia District, in North Gondar Administrative Zone. According to information obtained from the district health office, the district is divided into 44 kebeles (40 peasant associations and 4 urban kebeles). Two of the urban kebeles (sub-districts) are located in Kola Diba district and the remaining two are located in Chuahit and Gorgora kebeles. The total population of the district was estimated to be 299,968 at the time of the study. There is one health center, six health stations, and two health posts in the district that are owned by the government. Thirteen peasant associations are being served by CBRHAs, all of whom were trained by the Family Guidance Association of Ethiopia (FGAE). Family planning service in the district is provided by government health institutions and FGAE.

The source population were all women aged 15-49 years and who are the wives or heads of households (if she is not currently married) in the district. The study population were women aged 15-49 years in the selected kebeles (Kolla Diba kebele 01, Chillo, Meskelekirstos, and Mangie kebeles).

Assuming an $8.6 \%$ CPR (12), a 95\% confidence level and a $1.5 \%$ tolerable error, the total sample size required was calculated to be 1342 . To make the survey result representative of the district, a multistage sampling technique was used. Initially the kebeles were stratified by their distance from the nearby health institution. Accordingly 15 kebeles which are found within a $5 \mathrm{~km}$ radius from the nearest health institution were included in the first strata. The second strata consisted of 18 kebeles which are within a radius of 5-10 kms from the nearest health institution. The third strata consisted 11 kebeles which are above $10 \mathrm{kms}$ in radius from the nearest health institution. One urban (Kola Diba kebele 01) and one rural kebele (Chillo) were selected from the first strata. From the second and third strata Meskele Kirstos and Mangie were selected respectively. The kebeles were selected using the lottery method. After selection of the kebeles, the sample was distributed to the selected kebeles based on the number of households in each selected kebele. The sample distribution by the selected kebeles was 551, 307, 279, and 205 households for Kolla
Diba kebele 01, Chillo, Meskelekirstos, and Mangie, respectively. A systematic sampling technique was used for the selection of the households in each selected kebele. The wife in each household in the selected kebele responded to the questionnaire. If there was no married woman in a household, the female head of that household was interviewed.

The major independent variables were different sociodemographic characteristics like age, educational status, religion, occupation and residence. The major dependent variable was usage of family planning methods.

A questionnaire interview, which was prepared in the Amharic language, was used for data collection. Data was collected by 10 female students who have completed $10^{\text {th }}$ grade. The data collection was supervised by two supervisors. Ethical and scientific clearance was obtained from the Research and Publications Office of the University of Gondar. Further permission was obtained from the District Administration, District Health Office, and heads of kebele administrations. The respondents were verbally informed about the purpose of the study and were told that participation was on a voluntary basis. Data was entered and analyzed using EPI-INFO version 6 and SPSS statistical packages.

\section{Results}

A total of 1340 women responded to the questionnaire, yielding a response rate of $99.9 \%$. Five hundred fifty $(41.0 \%)$ of the respondents were from Kolla Diba town and the remaining $790(59.0 \%)$ were from the rural areas. The mean age of the respondents was 30.99 years $(\mathrm{SD}=$ 7.94). The majority of the women $(68.5 \%)$ and their husbands $(52.6 \%)$ are unable to read and write, 1018 $(76.0 \%)$ women were house wives, $1243(92.8 \%)$ were Orthodox Christians and 1131 (84.4\%) were married (Table 1).

Three hundred ninety two (71.3\%) respondents from Kolla Diba town had information about family planning and in the rural areas, $354(44.8 \%)$ had information about family planning. The major sources of information were the health center (54.3\%) and Community Based Reproductive Health Services (17.1\%). Five hundred nineteen $(69.6 \%)$ of those who reported that they have information about family planning defined family planning as "spacing between child births" and $122(16.4 \%)$ defined it as "spacing and limiting the number of children". Pills and injectables were known by $618(82.8 \%)$ respondents. Only one person mentioned the condom as a family planning method. No one mentioned about male sterilization methods while two people mentioned Norplant (Table 2).

Seven hundred and nineteen women (53.7\%) thought that family planning is important while $14(1.0 \%)$ said they didn't feel that family planning was important. Six 


\begin{tabular}{|c|c|c|}
\hline Socio-demographic Characteristic & Number $(\mathrm{N}=1340)$ & Percent \\
\hline \multicolumn{3}{|l|}{ Address } \\
\hline Kolla Diba & 550 & 41.0 \\
\hline Chillo & 307 & 22.9 \\
\hline Meskelekirstos & 279 & 20.8 \\
\hline Mangie & 204 & 15.2 \\
\hline \multicolumn{3}{|l|}{ Age } \\
\hline $15-19$ & 71 & 5.3 \\
\hline $20-24$ & 230 & 17.2 \\
\hline $25-29$ & 271 & 20.2 \\
\hline $30-34$ & 246 & 18.4 \\
\hline $35-39$ & 258 & 19.3 \\
\hline $40-44$ & 178 & 13.3 \\
\hline $45-49$ & 86 & 6.4 \\
\hline \multicolumn{3}{|l|}{ Education status of the women } \\
\hline Can't read \& write & 918 & 68.5 \\
\hline Grade $1-6^{*}$ & 219 & 16.3 \\
\hline Grade 7-8 & 57 & 4.3 \\
\hline Grade 9-12 & 140 & 10.4 \\
\hline $12+1$ and above & 6 & 0.4 \\
\hline \multicolumn{3}{|l|}{ Education status of the husband } \\
\hline Can't read and write & 595 & 52.6 \\
\hline Grade $1-6^{*}$ & 315 & 27.9 \\
\hline Grade 7-8 & 59 & 5.2 \\
\hline Grade 9-12 & 139 & 12.3 \\
\hline $12+1$ and above & 23 & 2.0 \\
\hline \multicolumn{3}{|l|}{ Religion } \\
\hline Orthodox Christian & 1243 & 92.8 \\
\hline Muslim & 95 & 7.1 \\
\hline Other & 2 & 0.1 \\
\hline \multicolumn{3}{|l|}{ Marital status } \\
\hline Married & 1131 & 84.4 \\
\hline Single & 21 & 1.6 \\
\hline Divorced & 108 & 8.1 \\
\hline Widowed & 80 & 6.0 \\
\hline \multicolumn{3}{|l|}{ Occupation } \\
\hline House wife & 1018 & 76.0 \\
\hline Local drink maker & 223 & 8.4 \\
\hline Farmer & 60 & 4.5 \\
\hline Government employ & 48 & 3.6 \\
\hline Merchant & 34 & 2.5 \\
\hline Student & 20 & 1.5 \\
\hline Other & 48 & 3.6 \\
\hline
\end{tabular}

${ }^{*}$ Educational status of Grade 1-6 also includes those who can read and write without formal education

hundred and seven of the respondents (45.3\%) said they didn't know about family planning and thus couldn't judge its importance. Three hundred and nine women (23.1\%) had ever used family planning methods. One hundred sixty five $(12.3 \%)$ are currently using family planning methods. Injectable contraceptives were used by 106 (64.2) clients; 57 (34.5) used pills and the remaining two $(1.2 \%)$ were using IUCD. A large proportion of the clients, in both urban (65.3\%) and rural (61.0\%) areas, are using injectable contraceptives (Table 2). One hundred sixty two $(14.3 \%)$ of the married women are currently using modern family planning methods. The current contraceptive prevalence rate in Kolla Diba town was $22.5 \%$, while in the rural areas as a whole, only 41 $(5.2 \%)$ are currently using contraceptives. The family planning coverage in Chillo, and Meskele Kirstos Peasant Associations was 7.5 and $6.5 \%$, respectively. There was no single user of family planning methods in Mangie Peasants Association, which was the remotest area selected for the study (Table 3).

A total of 144 (46.6\%) women who had ever used contraceptives discontinued taking contraceptives. The two most important reasons for discontinuing were 
perceived side effects of the contraceptives by 62 (43.1\%) and wanting to have more children by 50 (34.7\%) women.

One thousand and thirty one women had never used contraceptives because they wanted to have many children by $588(57.0 \%)$ and not knowing about family

Table 2: Information and practice of family planning among women of age 15-49 in Dembia District, April 2004.

\begin{tabular}{|c|c|}
\hline Variable & No (\%) \\
\hline \multicolumn{2}{|l|}{$\begin{array}{l}\text { Has information about family } \\
\text { planning }\end{array}$} \\
\hline Yes & $746(55.7)$ \\
\hline No & $594(44.3)$ \\
\hline Total & $1340(100.0)$ \\
\hline \multicolumn{2}{|l|}{ Source of information } \\
\hline Government health institution & $419(56.2)$ \\
\hline GBRHAs & $127(17.1)$ \\
\hline Mass media (radio \& television) & $86(11.5)$ \\
\hline Neighbors/relatives & $57(7.6)$ \\
\hline School & $24(3.2)$ \\
\hline Different sources & $33(4.4)$ \\
\hline Total & $746(100.0)$ \\
\hline \multicolumn{2}{|l|}{ Methods known } \\
\hline Pills only & $13(1.7)$ \\
\hline Injectables only & $29(3.9)$ \\
\hline Pills and injectables & $618(82.8)$ \\
\hline Pills and IUCD & $1(0.1)$ \\
\hline Three methods & $65(8 / 7)$ \\
\hline More than three methods & $14(1.9)$ \\
\hline Didn't mention any method & $6(0.8)$ \\
\hline Total & $746(100.0)$ \\
\hline \multicolumn{2}{|c|}{$\begin{array}{l}\text { Ever use of modern family planning } \\
\text { method }\end{array}$} \\
\hline Yes & $309(23.1)$ \\
\hline No & $103176.9)$ \\
\hline Total & $1340(100.0)$ \\
\hline \multicolumn{2}{|c|}{$\begin{array}{l}\text { Family planning methods currently } \\
\text { being used }\end{array}$} \\
\hline Injectables & $106(64.2)$ \\
\hline Pills & $57(34.5)$ \\
\hline IUCD & $2(1.2)$ \\
\hline Total & $165(100.0)$ \\
\hline
\end{tabular}

Table 3: Current users of family planning methods by residence, Dembia District, April 2004.

\begin{tabular}{llll}
\hline \multirow{2}{*}{ Residence } & \multicolumn{3}{c}{ Use family planning methods } \\
\cline { 2 - 4 } & Yes (\%) & No (\%) & Total (\%) \\
\hline Kolla diba & $124(22.5)$ & $426(77.5)$ & $550(100.0)$ \\
Chillo & $23(7.5)$ & $284(92.5)$ & $307(100.0)$ \\
Meskelekirstos & $18(6.5)$ & $261(93.5)$ & $279(100.0)$ \\
Mangie & $0(0.0)$ & $204(100.0)$ & $204(100.0)$ \\
\hline Total & $\mathbf{1 6 5 ( 1 2 . 3 )}$ & $\mathbf{1 1 7 5 ( 8 7 . 7 )}$ & $\mathbf{1 3 4 0 ( 1 0 0 . 0 )}$ \\
\hline
\end{tabular}

P-value $<0.001$

planning by $347(33.7 \%)$ women (Table 4$)$. Of those women who had never used contraceptives $728(70.5 \%)$ said they did not want to take contraceptives in the future, again the desire to have many children $(46.8 \%)$ being top among the list of reasons. Fear of side effects was also mentioned by $27(3.7 \%)$ women (Table 4$)$.

In the Bi-variate analysis, residence, distance from health institutions, age of the woman, education of the woman, education of the husband, occupation, and religion were found to be significantly associated with usage of contraceptives (P-value $<0.05$ ). Urban dwellers were 3.6 times more likely to use contraceptives compared to rural dwellers. Generally, it was found that there was increasing trend for using contraceptives as age increases. Those women who are 25-34 years old were 1.12 times more likely to use contraceptives compared with 15-24 years old ones. The more the women and their husbands are educated the more likely the use of contraceptives. Government employed women were 3.4 times more likely to use contraceptives compared with housewives. Followers of the Orthodox religion were found to be less likely to use contraceptives. On the contrary, there was no statistically significant association between the number of children ever born and the current use of contraceptives. In the multivariate analysis the age of the woman didn't show significant association with usage of contraceptives while the other variables showed significant association.

Table 4: Reasons for not ever using and not desiring of taking contraceptives in the future, Dembia District, April 2004.

\begin{tabular}{lll}
\hline Reason & Not ever using & Not desiring in future \\
\cline { 2 - 3 } & Number (\%) & Number (\%) \\
\hline Want to have many children & $588(57.0)$ & $341(46.8)$ \\
Don't know about family planning & $347(33.7)$ & - \\
No sexual intercourse/No intention of sexual intercourse in the future & $46(4.5)$ & $92(12.7)$ \\
Fear of side effects & $15(1.5)$ & $27(3.7)$ \\
Don't want to take & - & $208(28.6)$ \\
Other & $35(3.4)$ & $60(8.2)$ \\
\hline Total & $\mathbf{1 0 3 1 ( 1 0 0 0 . 0 )}$ & $\mathbf{7 2 8 ( 1 0 0 . 0}$ \\
\hline
\end{tabular}


Table 5: Factors associated with usage of contraceptives, Dembia District, April 2004.

\begin{tabular}{|c|c|c|c|c|c|}
\hline \multirow{2}{*}{ Factor } & \multicolumn{2}{|c|}{ Contraceptive use } & \multirow[t]{2}{*}{$\begin{array}{l}\text { Crude } \\
\text { OR }(95 \% \mathrm{Cl})\end{array}$} & \multirow[t]{2}{*}{$\begin{array}{l}\text { Adjusted } \\
\text { OR }\end{array}$} & \multirow[t]{2}{*}{ P-value } \\
\hline & Yes & No & & & \\
\hline \multicolumn{6}{|l|}{ Residence } \\
\hline Urban & 124 & $426^{*}$ & & & \\
\hline Rural & 41 & 749 & $0.19(0.13-0.24)$ & 0.503 & 0.12 \\
\hline \multicolumn{6}{|l|}{ Age of the Woman } \\
\hline $15-24$ & 38 & $263^{*}$ & & & \\
\hline $25-34$ & 72 & 445 & $1.12(0.72-1.74)$ & 1.275 & 0.365 \\
\hline $35-49$ & 55 & 467 & $0.82(0.51-1.30)$ & 0.926 & 0.730 \\
\hline \multicolumn{6}{|l|}{ Education of the Woman } \\
\hline Can't read \& Write & 55 & $863^{*}$ & & & \\
\hline Grade $1-6^{* *}$ & 44 & 175 & $3.95(2.51-6.19)$ & 3.805 & 0.000 \\
\hline Grade $7 \&$ above & 66 & 137 & $7.56(4.97-11.51)$ & 1.542 & 0.124 \\
\hline \multicolumn{6}{|l|}{ Education of the husband } \\
\hline Can't read \&Write & 36 & $559^{*}$ & & & \\
\hline Grade $1-6^{* *}$ & 45 & 270 & $2.59(1.59-4.21)$ & 2.621 & 0.002 \\
\hline Grade $7 \&$ above & 81 & 140 & $8.98(5.7-14.2)$ & 1.681 & 0.043 \\
\hline \multicolumn{6}{|l|}{ Occupation of the woman } \\
\hline House Wife & 120 & $898^{*}$ & & & \\
\hline Govt employ & 15 & 33 & $3.40(1.71-6.71)$ & 3.432 & 0.001 \\
\hline Others & 30 & 244 & $0.92(0.59-1.43)$ & 3.969 & 0.002 \\
\hline \multicolumn{6}{|l|}{ Religion } \\
\hline Orthodox Christian & 133 & $1110^{*}$ & & & \\
\hline Other & 32 & 65 & 4.11(2.53-6.66) & 1.935 & 0.18 \\
\hline
\end{tabular}

Foot not: *-Referent category

**-Grade 1-6 also includes those who can read and write without formal education

The P-value for all the bi-variate association shown in the table is $<0.05$

\section{Discussion}

Three hundred ninety two $(71.3 \%)$ respondents from Kolla Diba town and $354(44.8 \%)$ from the rural areas had information about family planning. This shows that still more than $50 \%$ of the women in the rural areas have no information regarding family planning. The major sources of information were the health center $(54.3 \%)$ and community based reproductive health services $(17.1 \%)$. It is encouraging that community based reproductive health agents are the second sources of information because this is a reliable means of reaching people at home. Five hundred nineteen (69.6\%) of those who have information about family planning defined family planning as "spacing" and $122(16.4 \%)$ defined it as "spacing and limiting the number of children". Even though spacing can limit the number of children, people should have in their mind both spacing and limiting in order to bring a sustainable reduction in the population growth. In previous studies conducted in North Gondar Zone, injectable contraceptives were not largely known $(12,13)$ but in this study pills and injectables were known by $618(82.8 \%)$ respondents. This shows that injectable contraceptives are becoming popular. The possible reason for this can be that injectables are taken every three months. Only one woman mentioned the condom as a family planning method. No one mentioned about male sterilization while two people mentioned Norplant. Those who are involved in promoting family planning services should, thus, focus on all methods of family planning whether or not the methods are available in their localities. What is surprising is that condom is being promoted for the purpose of HIV prevention but the contraceptive effect of condom is not largely known in this area.

Only seven hundred and nineteen women (53.7\%) thought that family planning is important. Six hundred and seven $(45.3 \%)$ didn't know about family planning and thus couldn't judge its importance. Sustainable efforts are needed to bring about behavioral change towards using family planning methods. Three hundred and nine women $(23.1 \%)$ had ever used contraceptives and $165(12.3 \%)$ are currently using family planning methods. Other studies conducted in the past in North Gondar Zone (which also included Dembia District) (12) and Dabat District (14) reported current prevalence rates of $8.6 \%$ and $2.4 \%$, respectively. In this regard the coverage found in Dembia District is higher. The reasons could be that either family planning service is increasing in the zone or this high coverage can be attributed to the plain topography of Dembia District which makes it possible to reach to most peasant associations by any available means of transportation. On the contrary, a study conducted in 1999 in Gondar town and the surrounding peasant associations (13) had reported current contraceptive prevalence rate of $28.6 \%$ (35.5\% in Gondar town \& $11.0 \%$ in the rural peasant associations found around Gondar Town), which is higher than the coverage found in this study. The reason could be that the people who are living in Gondar town are better educated and have better access to different family planning methods. The coverage in the 
surrounding peasant associations was also higher compared to the results of this study. One possible explanation for this is that people in the surrounding areas of Gondar have the opportunity to use the family planning services in Gondar town and the health institutions around Gondar. According to the 1995 (E.C) report of the Ministry of Health, the national and regional family planning coverage was $21.46 \%$ and $22.16 \%$, respectively (3). Considering the plain topography of the district, the coverage found in Dembia District could be considered low, which requires designing better strategies for family planning delivery. The current contraceptive prevalence rate in Kolla Diba town was $22.5 \%$ while in the rural areas as a whole, only $41(5.2 \%)$ are currently using contraceptives. Of the rural areas the family planning coverage in Chillo and Meskele Kirstos was $7.5 \& 6.5 \%$, respectively. There was no single user of family planning methods in Mangie Peasant Association, which was the remotest of the areas selected for the study. The coverage difference between Chillo and Meskelekirstos is low, being only $1 \%$. This narrow difference could be the result of the presence of CBRHAs in Meskelekirstos.

Only three methods were found to be used by the clients. These are injectables (64.2\%), pills (34.5) and IUCD $(1.2 \%)$. The wide use of injectables is in agreement with a study conducted in Gondar town and the surrounding areas (13). The fact that only three methods were used by the clients shows that family planning service providers depend only on the family planning methods which are available in health institutions found in Dembia District. The district needs to provide a wide range of family planning services like Norplant. Additionally, after providing appropriate information, clients could have been referred to Gondar town, which is only $35 \mathrm{kms}$ far from Kolla Diba, for the application of other methods like tubal ligation and vasectomy. This can improve the quality of family planning services in the area $(19,20)$.

The desire to have many children was mentioned by a large proportion of women as a reason for not ever using and not desiring to take contraceptives in the future. Other studies conducted in the past also revealed this fact $(12,13,14)$. It is a known tradition in Ethiopia that having many children is considered as an asset. This tradition should stop somewhere since this has an economic and social impact (21). Side effects caused by the methods were also mentioned by a significant number of women as a reason for discontinuing or not having the desire to take contraceptives in the future. It is true that each contraceptive has its own side effects. The service providers need to inform the clients and other eligible people who did not start using contraceptives, about the possible side effects of each method. By doing so clients can choose, in consultation with the provider, the method that is most appropriate for her/him. When side effects occur, the clients could come to the provider without too much fear since they have prior information about the method they are using $(19,20)$.

Regarding the factors that are associated with usage of contraceptives, it was found that urban dwellers are 3.6 times more likely to use contraceptives compared to rural dwellers. The more the women and their husbands are educated, the more likely they tend to use contraceptives. Government employed women were 3.4 times more likely to use contraceptives compared with housewives. A similar finding was also obtained in the study conducted in Gondar town and the surrounding areas (13). Since urban dwellers have better access to family planning services, and they are more likely to be better educated, it is likely for them to use contraceptives more than the rural dwellers.

\section{Limitations of the study}

This study was conducted only in one district, which makes generalization to wider areas difficult. This happened due to a shortage of budget to cover more districts. Income could be one of the factors that can affect the usage of contraceptives but in this study the estimation of income during data collection was not accurate so that it was not considered during the analysis.

\section{Conclusion and Recommendations}

The contraceptive prevalence rate in the study area is low considering the plain topography of the district. There was no modern family planning method user in remote areas. The presence of CBRHAs contributed to a relatively high coverage of family planning in Meskelekirstos district. Only a few methods are used in the district. Fear of side effects of the contraceptives was mentioned by a large number of women as a reason to discontinue or not having the desire to take contraceptives in the future. Based on the major findings of the study the following recommendations are forwarded:

1. Since static family planning services are not accessible to all eligible people, other strategies like outreach methods should be considered

2. More CBRHAs should be trained to give family planning services specially in remote areas. Probably in the future, if adequate number of Health Extension Workers are trained, the problem of access will be solved

3. All eligibles for family planning services need to be informed about the different family planning methods including their side effects.

4. Further study is required to assess the quality of family planning service in the area

\section{Acknowledgement}

I would like to thank the Research and Publication Office of the University of Gondar for sponsoring this research. Dembia woreda Administration, Dembia Woreda Health 
Office, and the heads of the selected kebeles are highly acknowledged for giving permission to conduct the study and for other cooperation. I would also like to extend my thanks to all women who had participated in the study, without whom the study couldn't have been possible.

\section{References}

1. Population Reference Bureau. World Population Data Sheet. 2004.

2. Central Statistical Authority. Ethiopia Demographic and Health Survey2000. Addis Ababa, Ethiopia; May 2001.

3. Ministry of Health. Health and Health Related Indicators. Planning and Programming Department, Federal Democratic Republic of Ethiopia; Addis Ababa, Ethiopia. 1995.

4. WHO. Maternal Mortality in 2000, Estimates developed by WHO, UNICEF and UNFPA. Geneva; 2004:11-19.

5. WHO. Reduction of Maternal Mortality. A Joint WHO/UNFPA/UNICEF/World Bank Statement. Geneva; 1999:20-33.

6. WHO. Progress in reproductive health research. Geneva; 2003: No.63.

7. WHO. SAFE MOTHERHOOD, Mother-Baby Package: Implementing safe motherhood in countries. Maternal health and safe Motherhood Programme, Division of Family Health, Geneva; 1994.

8. Viegas O.A.C, Wiknosastro G, Sahagun G.H, Chaturachinda K, and Ratnam S.S. Safe child birth needs more than medical services. An International Journal of Health Development; 1992; 13(1):59-65.

9. Ministry of Health. Health and Health Related Indicators. Planning and Programming Department, Federal Democratic Republic of Ethiopia, Addis Ababa, Ethiopia. 1992.

10. Ministry of Health. Health and Health Related Indicators. Planning and Programming Department, Federal Democratic Republic of Ethiopia, Addis Ababa, Ethiopia. 1993.

11. Ministry of Health. Health and Health Related Indicators. Planning and Programming Department, Federal Democratic Republic of Ethiopia, Addis Ababa, Ethiopia. 1994.
12. Ismael S, Damena M. Family planning survey in North Gondar, Ethiopia. Ethiopian Medical Journal; 1996 July; 34(3):173-181.

13. Kebede Y. Contraceptive prevalence and factors associated with usage of contraceptives around Gondar town. The Ethiopian Journal of Health Development 2000; 14(3):327-334.

14. Fantahun M, Kumbi S, Degu G, Kebede Y, Admassu M, Haile W, and Hailu S. Dabat Rural Health Project, northwest Ethiopia: Report of the baseline survey. The Ethiopian Journal of Health Development 2001; 15( Special issue).

15. Kaba M. Fertility regulation among women in rural communities around Jimma, Western Ethiopia. Ethiopian Journal of Health Development; August 2000; 14(2):117-125.

16. Central Statistical Authority. Fertility survey of Urban Addis Ababa. Statistical Bulletin. Population Analysis and Studies Center, Federal Democratic Republic of Ethiopia, Addis Ababa, Ethiopia. 1995:183.

17. Ministry of Health. Handbook and Guideline on Integrated MCH/FP Services. Federal Democratic Republic of Ethiopia, Addis Ababa, Ethiopia 1992:61.

18. Ayalew T, Dejene A, and Mekonnen Y. Unmet need and the demand for family planning service in Addis Ababa. The Ethiopian Journal of Health Development; April 1995; 9(1):41-45.

19. Johns Hopkins Population Information Program, World Health Organization, and USAID. The essentials of contraceptive technology. January 2001:1-22.

20. WHO. Improving access to quality care in family planning. Medical eligibility criteria for contraceptive use, Second Edition. Reproductive Health and Research, Geneva, Switzerland. 2000:117.

21. Robert A. Hatcher, Deborah K, Felicia G et al. Contraceptive technology: International Edition, Special Section on AIDS; Printed Matter, Inc. Atlanta, GA, USA; 1989:1-14. 
